\title{
SHIP deficiency causes Crohn's disease-like ileitis
}

\author{
William G Kerr, ${ }^{1}{ }^{12}$ Mi-Young Park, ${ }^{1}$ Monique Maubert, ${ }^{1}$ Robert W Engelman ${ }^{3}$
}

'Department of Microbiology \& Immunology, SUNY Upstate Medical University, New York, USA

2Department of Pediatrics,

SUNY Upstate Medical University, New York, USA ${ }^{3}$ Departments of Pathology \& Cell Biology and Pediatrics, H. Lee Moffitt Comprehensive Cancer Center and Research Institute, University of South Florida, Florida, USA

\section{Correspondence to} William G Kerr, SUNY Upstate Medical University, $750 \mathrm{E}$ Adams Street, 2204 Weiskotten Hall, Syracuse, NY 13210, USA; kerrw@upstate.edu

WGK and MYP contributed equally.

Revised 23 July 2010 Accepted 10 August 2010 Published Online First 12 October 2010

\section{ABSTRACT}

Background Inflammatory bowel disease (IBD) can arise from genetic mutations that compromise intestinal epithelial cell integrity or immune regulation. SHIP has previously been shown to play a pivotal role in limiting the number of immunoregulatory cells and their function. Aim To determine whether SHIP plays a pivotal role in control of immune tolerance in the gut mucosa.

Methods Gastrointestinal pathology was assessed in three separate strains of SHIP-deficient mice and their respective wild-type (WT) littermates. Gastrointestinal pathology was analysed in SHIP-deficient hosts reconstituted with WT haematopoietic cell grafts, and WT hosts reconstituted with SHIP-deficient

haematopoietic cell grafts including whole splenocytes, purified T cells or natural killer (NK) cells. Major immune cell populations were also analysed in the small intestine of SHIP-deficient mice and WT controls.

Results SHIP-deficient mice developed segmental, transmural pyo-granulomatous ilietis that recapitulated classical features of Crohn's disease enteric pathology. Analysis of haematopoietic chimeras showed that WT bone marrow reconstitution of SHIP-/- hosts corrects ileitis. Reconstitution with $\mathrm{SHIP}^{-/-}$splenocytes transferred ileitis to WT hosts. Adoptive transfer of purified SHIP ${ }^{-1-}$ T cells or NK cells to WT hosts did not transfer ileitis. There was a paucity of both CD4 and CD8 $T$ cells in the small intestines of SHIP-deficient mice; however, neutrophil numbers were significantly increased.

Conclusions SHIP plays a pivotal role in immune function in the intestine; further scrutiny of this pathway in IBD patients is warranted. It is proposed that SHIP-deficient ileitis results from a local deficit in mucosal $\mathrm{T}$ cell immunity that promotes a damaging granulocyte-monocyte inflammation of the distal ileum.

\section{INTRODUCTION}

Crohn's disease $(\mathrm{CD})$ is a chronic, relapsing idiopathic inflammatory bowel disease (IBD) that can affect various sites within the gastrointestinal tract, but classically the ileum, which leads to abdominal cramping, diarrhoea and gastrointestinal bleeding. ${ }^{1-4} \mathrm{CD}$ histopathological lesions begin with the formation of multiple aphthoid ulcers infiltrated by neutrophils, which progress and coalesce into sharply delimited, regional, transmural inflammations with granuloma formation, thickening of the muscularis propria, strictures, fissures and fistulas. ${ }^{1-4}$ Although genome-wide association studies have identified more than 30 susceptibility loci for IBD that disturb either intestinal epithelial cell (IEC) barrier homeostasis or immune effector cell functions and interactions with luminal flora and antigens, ${ }^{5-7}$ many susceptibility genes possess differing functions in IEC and

\section{Significance of this study}

What is already known about this subject?

- Immune regulation is critical for the integrity and function of the small intestine.

- SHIP controls the homeostasis of immunoregulatory myeloid and T lymphoid cells in peripheral lymphoid tissues such as spleen and lymph node.

- Myeloid consolidation of the lungs is a significant cause of morbidity and mortality in SHIPdeficient mice.

What are the new findings?

- Despite enhanced immune regulation in the peripheral lymphoid tissues of SHIP-deficient mice, immune function and regulation is compromised in the small intestine of these mice.

- Normal immune function and homeostasis in the small intestine requires enzymatically active SHIP.

- Expression of SHIP by intestinal epithelial cells is not required for the integrity of the small intestine.

- SHIP-deficient haematolymphoid cells are sufficient to transfer ileitis to wild-type hosts.

- There is a paucity of both CD4 and CD8 T cells in the small intestine of SHIP-deficient mice.

- There is local neutrophilia in the small intestines of SHIP-deficient mice.

\section{How might it impact on clinical practice in the foreseeable future?}

- These findings suggest that detailed analysis of the SHIP gene is warranted in human IBD patients and may also lead to a better understanding of immune cell signalling pathways required for immune function and regulation in the human gut.

haematopoietic cells, and primary IEC or immunological defects in genetically susceptible individuals often remain enigmatic. ${ }^{89}$

Primary immunological alterations proposed to contribute to the development of CD pathology include increased expression of Th1-polarising cytokines interleukin (IL)-12 and interferon $\gamma$ by cells in the lamina propria, ${ }_{10} 11$ aberrant IL-23initiated Th17-associated immune responses, ${ }^{12}{ }^{13}$ defects in regulatory $\mathrm{T}$ cell (Treg) modulation of effector functions via transforming growth factor $\beta$ or IL-10 dependent mechanisms, ${ }^{14}$ aberrant B-cell specificity and serum autoreactivity ${ }^{15}$ and myeloid cell dysfunction. ${ }^{16}$ That primary defects in immune cell function contribute to $\mathrm{CD}$ in some patients is supported by reports of disease remission following allogeneic bone marrow transplantation. ${ }^{17}$ his paper is freely available online under the BMJ Journa gut.bmi.com/site/about/ unlocked.xhtml 
IEC barrier defects that may contribute to CD development include the inability of a Paneth cell-derived NOD2 variant to expel luminal bacteria, ${ }^{18}$ diminished IEC autophagy and antimicrobial granule exocytosis, ${ }^{19}$ altered IEC toll-like receptor expression with potentially dysregulated responses to common bacterial motifs, ${ }^{20}$ altered IEC cytokine expression ${ }^{21}$ and increased IEC paracellular permeability to enteric luminal contents, perhaps due to inadequate formation of IEC tight junctions. ${ }^{22}$

Although animal models of IBD have been described, most model systems affect the large intestine, do not manifest $\mathrm{CD}$-specific histopathological features, and are often induced rather than spontaneously developing models. 523 Only two animal models spontaneously develop chronic inflammation of the ileum, the SAMP1/Yit mouse $e^{24}$ and the TNF ${ }^{\triangle A R E}$ mouse. ${ }^{25}$ SAMP1/Yit mice spontaneously develop terminal ileitis by 10 weeks of age driven by Th1- and Th2-type immune responses, the severity of which can be decreased by antitumour necrosis factor (TNF) antibodies. ${ }^{23} 26 \quad 27$ Although SAMP1/Yit mesenteric lymph node $\mathrm{CD} 4^{+}$T cells are capable of adoptively transferring ileitis to severe combined immunodeficient (SCID) mice, increased IEC paracellular permeability appears to be the primary susceptibility factor in this model. ${ }^{22}$ The TNF ${ }^{\triangle A R E}$ mouse model was generated by deletion of $69 \mathrm{bp}$ within the AU-rich region (ARE) of the gene that encodes TNF, resulting in increased systemic TNF levels associated with expansion of $\mathrm{CD}^{+}$effector cell subpopulations that mediate chronic ileitis and arthritis in both heterozygous and homozygous mice. $^{2528}$ Haematopoietic cells of neither the SAMP1/Yit nor the $\mathrm{TNF}^{\triangle \mathrm{ARE}}$ mouse are capable of adoptively transferring CD-like disease to an immunocompetent host.

The Src homology 2 (SH2)-containing inositol-5-phosphatase (SHIP) protein becomes tyrosine phosphorylated in haematopoietic cells following activation of surface receptors for various cytokines including erythropoietin, IL-3, GM-CSF, M-CSF, or in response to $\mathrm{B}$ cell antigen receptor cross-linking, or $\mathrm{T}$ cell activation. $^{29} 30$ SHIP signalling plays a pivotal role in limiting the number and function of immunoregulatory cells in the peripheral lymphoid system. ${ }^{31-37}$ We recently found that SHIP limits the number of immunoregulatory $T$ cells present in the spleen and mesenteric lymph nodes. ${ }^{35}$ SHIP performs this role by controlling the number of Treg cells in the periphery either by limiting the survival of FoxP3 ${ }^{+}$Treg cells or by preventing the inappropriate acquisition of FoxP3 expression by naïve CD4 T cells. ${ }^{35}$ Consistent with this finding, the p110 subunit of an enzyme that SHIP opposes, PI3K, is critical for the formation and survival of Treg cells in the periphery. ${ }^{38} 39$ SHIP-deficiency also promotes the inappropriate expansion of myeloid immunoregulatory (MIR) cells in spleen and lymph nodes. ${ }^{32} 33$ Thus, in major peripheral lymphoid tissues like spleen and lymph node, SHIP-deficiency leads to profound and functional expansion of immunoregulatory capacity. In aggregate these studies establish that inositol phospholipid signalling plays a pivotal role in the formation, homeostasis and function of both myeloid and lymphoid immunoregulatory cell populations.

SHIP, through its $5^{\prime}$-inositol phosphatase domain, hydrolyses the second messenger $\mathrm{PI}(3,4,5) \mathrm{P}_{3}$ and thus limits $\mathrm{PI} 3 \mathrm{~K}$ activation of key downstream immune effector pathways such as Akt and NF- $\kappa B .{ }^{30} 40$ SHIP-deficient mice are smaller than their WT and heterozygous littermates and exhibit a greatly reduced lifespan with survival beyond 10-12 weeks of life observed only rarely, ${ }^{32} 41$ attributable in part to the development of an eosinophilic crystalline pneumonia with infiltration by mixed inflammatory cells resulting in patchy lung consolidation. ${ }^{41}$ Eosinophilic crystalline pneumonia is a cause of shortened life span in various genetically engineered mouse models. ${ }^{42}{ }^{43}$ Granulocytes are less susceptible to apoptotic signals in SHIP-deficient mice, and granulocyte-monocyte infiltrations can be found in the liver, kidney, heart, skeletal muscle, pancreas lymph nodes and thymus. ${ }^{44}$ The increased capacity of SHIP-deficient $\mathrm{T}$ cells to differentiate into Treg cells is accompanied by a deficiency in Th17 cell differentiation and a reduced ability to cause colitis after adoptive transfer of $\mathrm{CD}^{+}{ }^{+}$T cells to T cell deficient hosts. ${ }^{35} 36$

Although SHIP expression and function has generally been thought to be confined to cells in the haematopoietic system, recent evidence indicates that SHIP is also expressed by some parenchymal cell types, including osteoblasts ${ }^{45}$ and endothelial cells. ${ }^{46}$ In fact, we recently identified the first known function for SHIP outside the haematolymphoid compartment as SHIP is required for support of haematopoietic stem cell function and quiescence by bone marrow (BM) niche cells. ${ }^{45}$

Given its role in immune regulation and lymphoid function we sought to examine whether SHIP-deficiency might have consequences at enteric mucosal surfaces where greater stress is placed on both immune effector and regulatory processes due to the close and constant interaction with commensal microflora and potential pathogens at this organ site. Surprisingly, our analysis reveals a paucity of both CD4 and CD8 T cells in the small intestine with a concomitant increase in neutrophils at this site. Consistent with altered immune status we find spontaneous development of ileitis with features that closely recapitulate those of CD pathology. In addition, the susceptibility factor for this CD-like ileitis of SHIP-deficient mice appears to be in the haematopoietic compartment, and likely granulocytemonocyte, as the CD-like ileitis was transferable to an immunocompetent host following irradiation and reconstitution with SHIP splenocytes, but not following transfer of either T cells or natural killer (NK) cells. Consequently, the SHIP-deficient mouse is the first CD animal model capable of adoptively transferring CD-like disease to an immunocompetent host.

\section{MATERIALS AND METHODS \\ Mice}

The development and production of $\mathrm{SHIP}^{-/-}$mice has been described previously. In brief $\mathrm{SHIP}^{-1-}$ mice were generated by deletion of the promoter and first exon of SHIP via a Cre-LoxP strategy and then backcrossed to the C57BL6/J background. SHIP ${ }^{\Delta \mathrm{IP} / \Delta \mathrm{IP}}$ mice were a kind gift of Dr Jeffery Ravetch (Rockefeller University, New York). ${ }^{47} \mathrm{MxCreSHIP}$ flox/flox mice were described previously. ${ }^{33}$ SHIP expression is ablated in these mice following three intraperitoneal injections of polyl/C at $625 \mu /$ dose. MxCreSHIPflox/llox mice were sacrificed for tissue harvest 4-5 weeks after the last polyI/C injection. The PI3K haploinsufficient $\mathrm{SHIP}^{-/-}$mice analysed in this study possess a mutation in the p85 regulatory subunit of $\mathrm{PI}^{3} \mathrm{~K}^{48}$ and a SHIP mutation created by Helgason et al. ${ }^{41}$ All mice were between 6 and 13 weeks of age at time of sacrifice. All mice were maintained in an accredited, barrier facility confirmed free of a comprehensive list of potential parasites and microbial pathogens including Citrobacter rodentium, Pseudomonas aeruginosa, Salmonella spp., and Clostridium perfringens, viral Antibodies to murine norovirus (MNV), parainfluenza virus type I (Sendai), coronavirus (MHV), Mycoplasma pulmonis, paramyxovirus (PVM), parvovirus (MPV, MMV), poliovirus (TMEV) reovirus type 3 (Reo), arterivirus (LCM), adenovirus (MAD1, MAD2), poxvirus (Ectro), rotavirus (EDIM), papovavirus (Poly), and free of Helicobacter sp. by PCR screening. Further, microorganisms were not identified in any tissue using WarthineStarry, Giemsa, Ziehle Neelsen and PAS stains. 


\section{Adoptive transfer experiments}

BM cells were flushed from intact femur and tibia and collected in tissue media (TM) consisting of RPMI, 3\% fetal bovine serum (FBS) and $10 \mathrm{mM}$ HEPES (Invitrogen, Carlsbad, California, USA). Spleens were crushed with a $10 \mathrm{ml}$ syringe plunger. The single cell suspension was then filtered through a $70 \mathrm{~mm}$ strainer (BD Bioscience, San Jose, CA) and red blood cell (RBC) lysis performed at room temperature for $5 \mathrm{~min}$ in $1 \times \mathrm{RBC}$ lysis buffer (eBioscience, San Diego, California, USA). Cells were centrifuged and resuspended in $1 \times$ Dulbecco phosphate-buffered saline (D-PBS). C57BL/6 recipients were given antibiotic water prior to receiving a split dose of 1100 Rads $(600+500)$ from an x-ray irradiator. Irradiated recipients were then transplanted with $5 \times 10^{5} \mathrm{BM}$ cells or splenocytes as indicated via retro-orbital injection. For adoptive transfer of $\mathrm{T}$ and $\mathrm{NK}$ cells, $\mathrm{CD}^{+} \mathrm{NKp}^{-} 6^{-}$ $\mathrm{T}$ and $\mathrm{NKp} 46^{+} \mathrm{CD}^{-} \mathrm{NK}$ cells were simultaneously sorted from spleens of $\mathrm{SHIP}^{-1-}$ mice and adoptively transferred into irradiated C57BL6 hosts (550 Rads) via retro-orbital injection. Each $\mathrm{C} 57 \mathrm{BL} / 6$ host received $2.4 \times 10^{5} \mathrm{SHIP}^{-1-} \mathrm{T}$ cells and $7.5 \times 10^{3}$ $\mathrm{SHIP}^{-/-}$NK cells.

\section{Histopathological analysis}

Necropsies were performed in a systematic, comprehensive manner. The entire alimentary tract, including the oesophagus, stomach, duodenum, jejunum, ileum, caecum, and colon and associated mesentery and mesenteric lymph nodes was evaluated, and the alimentary tract was insufflated with 10\% neutralbuffered formalin and rolled in segments to fit as Swiss rolls into cassettes for histological processing and microscopic evaluation. The skin, subcutis, skeletal muscle, inguinal lymph node and mammary fat pad, cervical lymph node, salivary glands, reproductive tract and associated glands, liver, gall bladder, spleen, pancreas, kidneys and adrenal glands, were evaluated. The larynx, trachea with attached thyroid and parathyroid glands, heart, thymus, and lungs insufflated with 10\% neutral-buffered formalin were collected. Tissues were fixed in 10\% neutralbuffered formalin, dehydrated, embedded in paraffin, sectioned at $3 \mu \mathrm{m}$ and stained with $\mathrm{H} \& \mathrm{E}$. Histological sections of each segment of the alimentary tract were masked, assessed and assigned an inflammatory grade of $0-6$, with grade 6 representing the most progressed, severe lesion. Inflammatory grades assigned were as follows: inflammatory grade $0=$ no significant abnormalities; inflammatory grade $1=$ mild predominantly polymorphonuclear (PMN) leucocyte infiltrations (<25 PMN/ hpf) of the lamina propria and/or enteric lymph nodule; inflammatory grade $2=$ moderate predominantly PMN leucocyte infiltrations ( $>25$ cells/hpf) of the lamina propria and/or lymph nodule; inflammatory grade $3=$ marked inflammatory cell infiltrations with extension below the muscularis mucosa causing architectural distortion of the mucosa and submucosa with attendant crypt hyperplasia; inflammatory grade $4=$ marked infiltrations with extension into the tunica muscularis; inflammatory grade $5=$ marked transmural leucocyte infiltrations; inflammatory grade $6=$ marked transmural leucocyte infiltrations with extension into the mesentery and/or other organs. In each section the presence of granuloma, crypt abscess, stricture, fissure, and whether dissemination of inflammation to other sites had occurred was noted. Inflammatory scores were compared between cohorts by one-way ANOVA. All reported $\mathrm{p}$-values are two-sided with $\mathrm{p}<0.01$ considered significant. The sections were scored by a single, board certified veterinary pathologist. The sections were scored by a veterinary pathologist with confirmation of scoring system and subsequent gradations by a clinical pathologist.

\section{Flow cytometry}

The antibodies used for staining of cells prepared from small intestines included CD3 $\varepsilon, \mathrm{CD} 4, \mathrm{CD} 8, \mathrm{CD} 16 / 32$, CD62L, CD62E and Ly6G and were obtained from BD Pharmingen (San Jose, California, USA). Samples were acquired on a FACSCalibur and analysed using FlowJo8. Dead cells were excluded from the analysis following cytometer acquisition of staining data based on exclusion of the DAPI dye.

\section{RESULTS}

\section{Ileitis in SHIP-deficient mice}

Seventy-nine 6-8 week old mice, including $26 \mathrm{SHIP}^{-1-}$ mice, $26 \mathrm{SHIP}^{\Delta \mathrm{IP} / \Delta \mathrm{IP}}$ mice, one $\mathrm{PI}^{+} \mathrm{K}^{+/-} \mathrm{SHIP}^{-1-}$ and 26 wild type littermates, each of both sexes were submitted to systematic, comprehensive necropsies, with histopathological examination of the entire insufflated alimentary tract. Primary gastrointestinal lesions were present only within the ileum of SHIP-deficient mice, and consisted of a segmental ileitis. Lesions were graded according to the extent of inflammation as grade $0-6$ (figures $1-6$ ). Of the 53 SHIP-deficient mice evaluated, only 3 of the $53(6 \%)$ of SHIP-deficient mice lacked ileitis, while 50 of the 53 (94\%) of SHIP-deficient mice had some degree of ileitis, significantly more than the absence of ileitis in WT littermates $(p<0.001)$. Both $\mathrm{SHIP}^{-/-}$and $\mathrm{SHIP}^{\Delta \mathrm{IP} / \Delta \mathrm{IP}}$ that harbour deletions in exons encoding different regions in the SHIP1 locus developed ileitis with comparable frequency with 25 of 26 (96\%) of SHIP ${ }^{-1-}$ mice, and 24 of $26(92 \%)$ of SHIP ${ }^{\Delta I P / \Delta I P}$ mice affected with comparable mean ileitis inflammatory grades of $4.2 \pm 2.1$ and $4.0 \pm 2.2$, respectively. Ileitis was also observed in a $\mathrm{PISK}^{+/-} \mathrm{SHIP}^{-/-}$mouse (grade 4), indicating that a third independent SHIP mutant strain develops this pathology and that PI3K haploinsufficiency does not protect from development of ileitis. PI3K ${ }^{+/-} \mathrm{SHIP}^{+/+}$and $\mathrm{PI} \mathrm{K}^{+/-} \mathrm{SHIP}^{+/-}$controls showed no evidence of ileitis (grade 0 ). Inflammatory lesions of the ileum in all SHIP-deficient mice analysed were present on a background of otherwise unaffected, uninflamed gastrointestinal tract.

The earliest manifestation of CD-like ileitis in SHIP-deficient mice, assigned grade 1 , consisted of a mild ( $<25 \mathrm{PMN} / \mathrm{hpf}$ ), predominantly PMN leucocyte infiltration of the lamina propria and frequently underlying lymph nodule (figure 1). The ileum of 9 of the 53 (17\%) of the SHIP-deficient mice had grade 1 lesions. This mild, earliest lesion of the SHIP-deficient ileum had progressed in other individual $\mathrm{SHIP}^{-/-}$and SHIP ${ }^{\Delta \mathrm{IP} / \Delta \mathrm{IP}}$ mice to a moderate (>25 $\mathrm{PMN} / \mathrm{hpf}$ ), mixed, but still predominantly PMN leucocyte infiltration of the expanded lamina propria and underlying lymph nodule, assigned grade 2, with attendant crypt regenerative hyperplasia manifest as IEC crowding, and elongation of crypt depth (figure 2). Grade 2 ileitis was present in 2 of the 53 (4\%) of SHIP-deficient mice. Grade 3 inflammatory cell infiltrations were mixed and penetrated below the muscularis mucosa with distortion of villous architecture by the expanded mucosa and submucosa, and attendant crypt hyperplasia (figure 3). Five of the $53(9 \%)$ of SHIP-deficient mice had grade 3 inflammatory lesions within the ileum.

Marked, mixed inflammatory cell infiltrations of the ileum of SHIP-deficient mice extending from the mucosa, submucosa, and into the tunica muscularis were assigned grade 4 (figure 4). Six of the $53(11 \%)$ of SHIP-deficient mice had grade 4 inflammatory lesions within the ileum. Composition of grade 4 inflammation varied from predominantly $\mathrm{PMN}$ in some segments to predominantly mononuclear in others, often as a mix of granulocytes, lymphocytes, histiocytes and multinucleated giant cells (figure 4D,E). Inflammatory cell infiltrations that extended into the tunica muscularis were segmental, sharply delimited, 
Figure 1 Grade 1 Crohn's disease (CD)-like ileitis of SHIP-deficient mice. Longitudinal sections through Swiss rolls of small intestine from SHIPdeficient mice with early manifestations of CD-like disease, interpreted as grade 1 , with mild predominantly polymorphonuclear (PMN) leucocyte infiltration of the lamina propria $(B$, arrows). This PMN infiltration of the ileum was typically present in the mucosa overlying and within lymph nodules $(\mathrm{C}-\mathrm{F})$. Adjacent ileum and more proximal small intestine $(C$, asterisk) were unaffected with normal villous mucosal architecture. Higher magnifications show a predominantly PMN leucocyte infiltration of the villous lamina propria $(\mathrm{F})$, and within the underlying lymph nodule, in this case accompanied by histiocytes and multinucleated giant cells $(\mathrm{E})$.
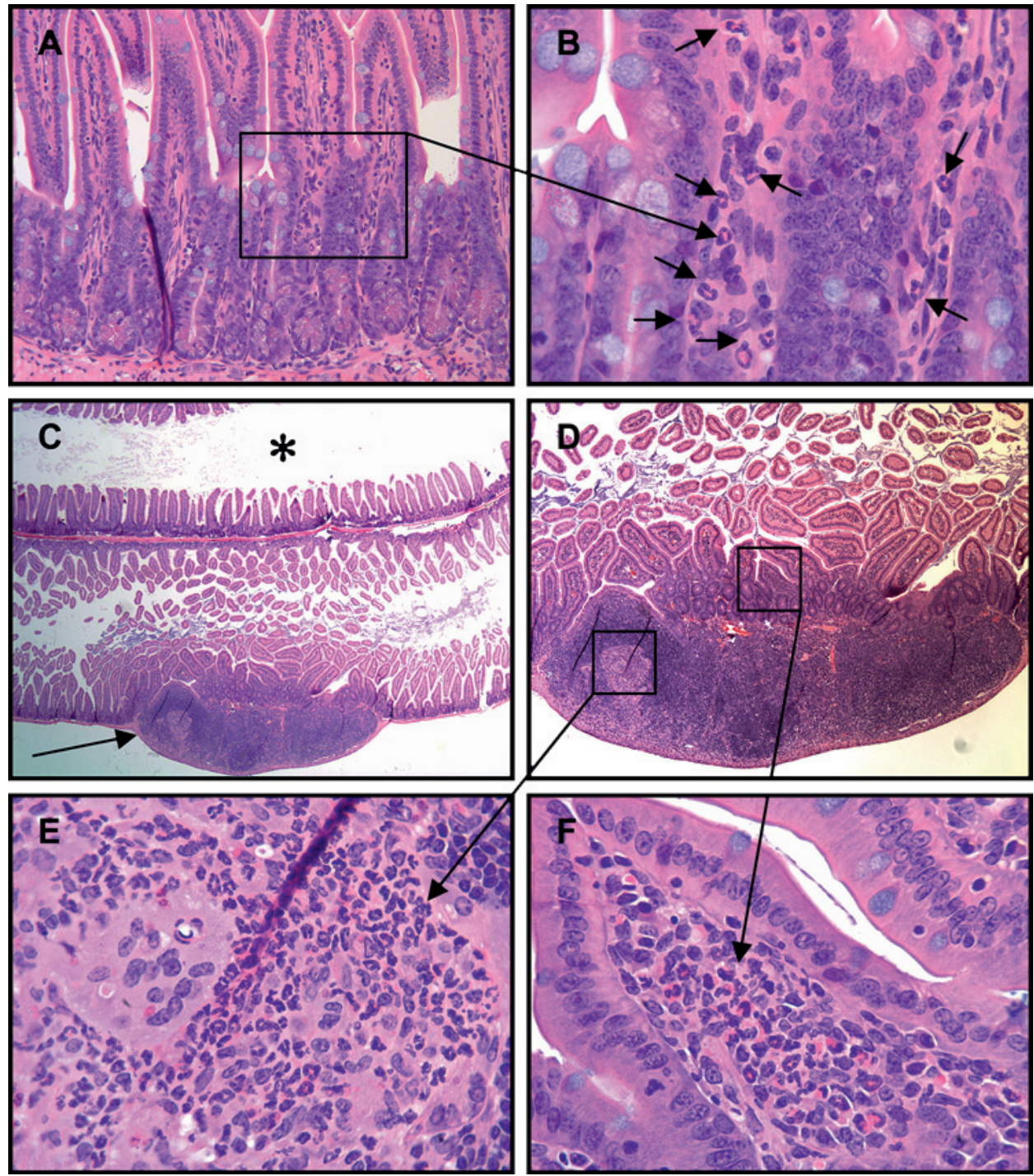

and arranged either randomly or as rows of aggregates in rosarybead arrays (figure 4F). In some areas of grade 4 inflammation the overlying mucosa was focally ulcerated. Granulomas and pyo-granulomas were present in the mucosa, submucosa and/or tunica muscularis. Thickening of the bowel wall due to grade 4 inflammation resulted in lumen narrowing and stricture formation in some mice (figure 4G)

Marked, mixed inflammatory cell infiltrations that extended transmural, deep into the bowel wall to the serosa, assigned grade 5 (figure 5), were present in 5 of the 53 (9\%) of SHIPdeficient mice. In some cases, grade 5 ileitis thickened the bowel wall, narrowed the lumen, led to stricture formation and the development of fissures that penetrated into and ended blindly within the tunica muscularis (figure $5 \mathrm{~A}, \mathrm{~B}$ ).

SHIP-deficient mice with marked, mixed, transmural inflammatory cell infiltrations of the ileum that extended by way of fissures through the thickened tunica muscularis and serosa into the mesentery (figure 6A-C) were assigned grade 6. More SHIPdeficient mice were assigned inflammatory grade 6 than any other grade with 23 of the 53 (43\%) of SHIP-deficient mice assigned ileitis grade 6. Inflammation extending into the mesentery consisted of mixed inflammatory cells, granuloma, fibrosis, and rarely thrombosis and vasculitis (figure 6D-F).

Ileitis of SHIP-deficient mice of all grades 1-6 was segmental, presenting either as focal, discontinuous inflammatory cell infiltrations or as broad bands of inflammation within the ileum (figure 7A-C). Neighbouring segments of ileum and those of more proximal small intestine or distal large intestine were unaffected. Strictures were observed in 12 of 53 (23\%) of SHIPdeficient mice (figure 4G), granuloma were present in 15 of 53 (28\%) (figure 4I), and crypt abscesses were observed in 5 of 53 (9\%) of SHIP-deficient mice (figure $4 \mathrm{~J}$ ). Pyloric metaplasia of the ileum, and fistula formation, other characteristics of CD histopathology in humans, were not evident in SHIP-deficient mice.

Rarely, ileitis spread by direct extension to other gastrointestinal sites, including in two mice where inflammation of the ileum extended via the mesentery to the colon wall (figure 8A,B), and in a third SHIP-deficient mouse where inflammation had spread to the gastro-oesophageal juncture (figure 8C,D). Draining mesenteric lymph nodes were often enlarged and inflamed in 33 of $53(62 \%)$ of SHIP-deficient mice (figure 8E,F). An individual $\mathrm{SHIP}^{-/-}$mouse had inflammatory cellular thrombi in mesenteric veins and a granulomatous pulmonary consolidation comparable in composition to the ileitis in this case, suggesting that vascular thrombi and emboli may rarely develop as a consequence of CD-like ileitis in SHIP-deficient mice and may disseminate inflammation via haematogenous routes (figure $8 \mathrm{G}-\mathrm{J}$ ). This pulmonary consolidation was distinct from that which occurs routinely in $\mathrm{SHIP}^{-/-}$and SHIP ${ }^{\Delta \mathrm{IP} \Delta \mathrm{IP}}$ mice as an eosinophilic crystalline pneumonia (figure $9 \mathrm{~A}-\mathrm{F}$ ) 
Figure 2 Grade 2 Crohn's disease-like ileitis of SHIP-deficient mice was comprised of a moderate, mixed, predominantly polymorphonuclear leucocyte infiltration of the ileum lamina propria (D) and underlying lymph nodule (C), with attendant crypt hyperplasia (B, upper bracketed arrows) with elongation, crowding, and numerous mitotic figures (D), compared to the unaffected mucosa of the adjacent small intestine ( $A$, asterisk) with normal villous architecture and typical crypt depth (B, lower bracketed arrows).
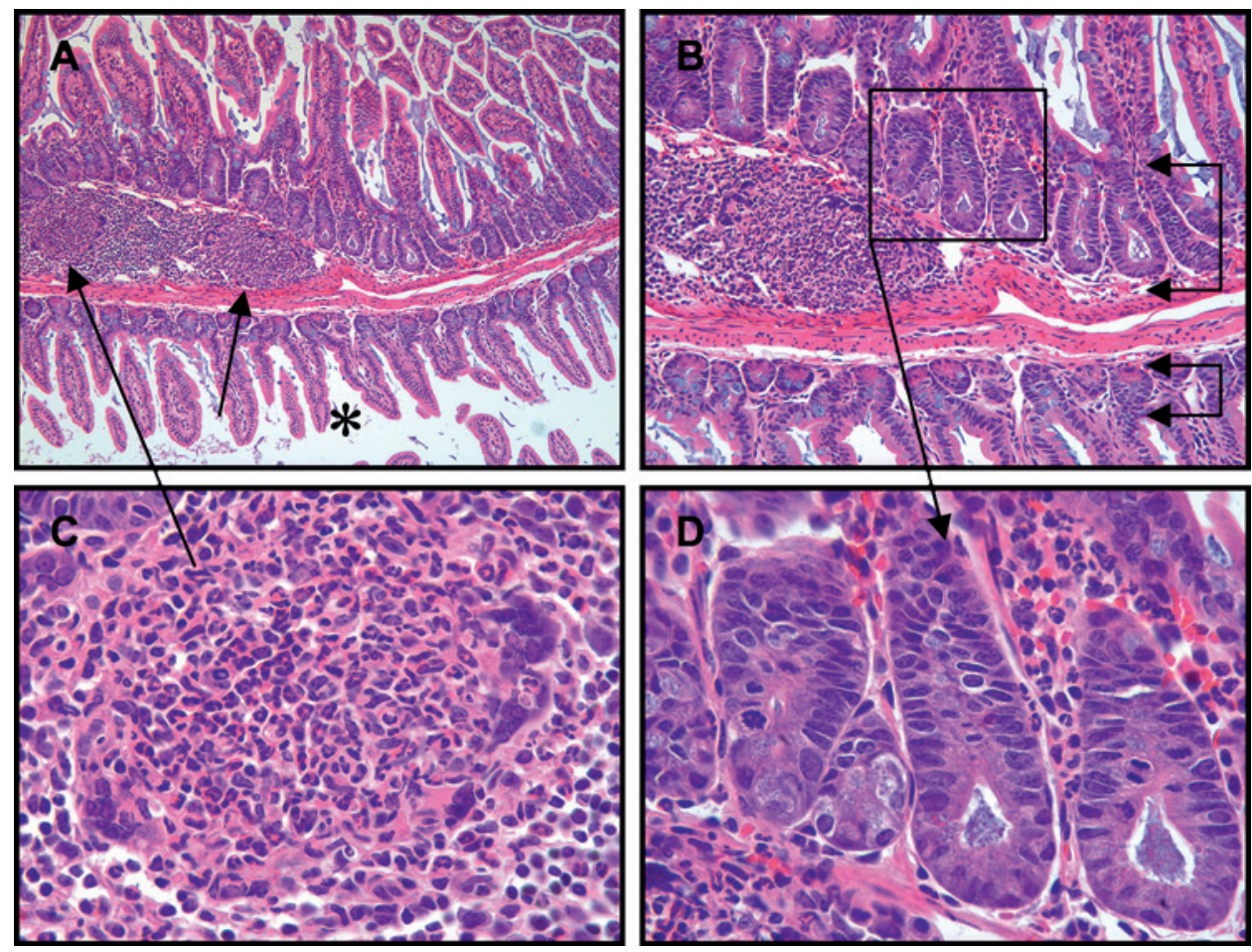

llietis results following ablation of SHIP expression in adulthood The above studies show that ileitis occurs in germline SHIP mutant mice, indicating this CD-like pathology may have a developmental origin. To test this possibility we analysed intestinal pathology in MxCreSHIP ${ }^{\text {flox/lox }}$ mice where SHIP expression is normal in fetal, neonatal and adolescent life, but can be ablated during adulthood following polyl/C administration. ${ }^{33}$ This approach results in eosinophilic crystalline pneumonia in adult mice rendered SHIP deficient. ${ }^{49}$ For this analysis twelve 6-8 week old MxCreSHIPflox/flox mice and twelve SHIfflox/flox controls, each of both sexes were submitted to comparable histopathological analyses. Primary gastrointestinal lesions were present only within the ileum of MxCreSHIPflox/flox mice, while SHIf flox/flox mice were unaffected $4-5$ weeks after the last injection of polyl/C. Of the $12 \mathrm{MxCreSHIPflox/llox}$ mice evaluated, only 1 (8\%) lacked ileitis, while 11 of 12 (92\%) developed ileitis with a mean inflammatory grade of $3.5 \pm 1.9$. Comparable to ileitis of SHIP ${ }^{-/-}$and SHIP ${ }^{\Delta \mathrm{IP} / \Delta \mathrm{IP}}$ mice, ileitis of MxCre SHIP flox/flox mice was segmental in nature with mixed inflammatory cell infiltrations. Granuloma formation was evident in 2 of 12 (17\%) of MxCreSHIPflox/flox mice. Thus, CD-like ileitis develops with selective deletion in adult mice, illustrating that SHIP expression is required to maintain normal mucosal immune homeostasis and regulation in the adult ileum.

\section{SHIP-deficient parenchymal cells do not cause ileitis}

To assess the possibility that SHIP-deficiency might alter the development or function of parenchymal cell types in the ileum such as the IEC, we created bone marrow (BM) chimeras where six $\mathrm{SHIP}^{-/-}$hosts were reconstituted with WT C57BL/6 BM and analysed histopathologically 4 months post-transplantation. The gastrointestinal tract of the six $\mathrm{SHIP}^{-/-}$hosts reconstituted with WT BM lacked any abnormalities including all features of the CD-like ileitis observed in germline $\mathrm{SHIP}^{-/-}$and SHIP ${ }^{\mathrm{IIP} / \Delta \mathrm{IP}}$ mice. We also analysed the lungs of these reconstituted mice. Although components of a moderate eosinophilic crystalline pneumonia were present in the $\mathrm{SHIP}^{-/-}$hosts reconstituted with WT C57BL/6 BM, including crystal formation, and an increase in the number of alveolar macrophages, the marked myeloid infiltration and pulmonary consolidation observed in $\mathrm{SHIP}^{-/-}$and
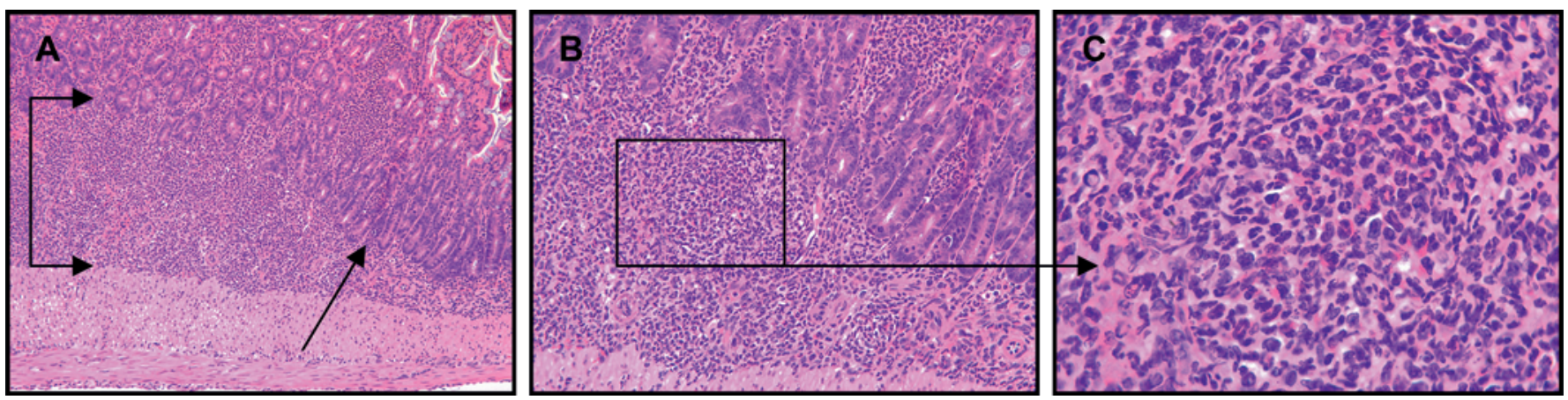

Figure 3 Grade 3 Crohn's disease-like ileitis of SHIP-deficient mice was comprised of a marked, mixed, often predominantly polymorphonuclear (PMN) inflammatory cell infiltration of the ileum with expansion of the mucosa and submucosa ( $A$, bracketed arrows), loss of normal villous architecture, and crypt elongation ( $A$, arrow). Higher magnifications of the affected ileum $(B, C)$ showed a mixed, predominantly PMN leucocyte infiltration. 

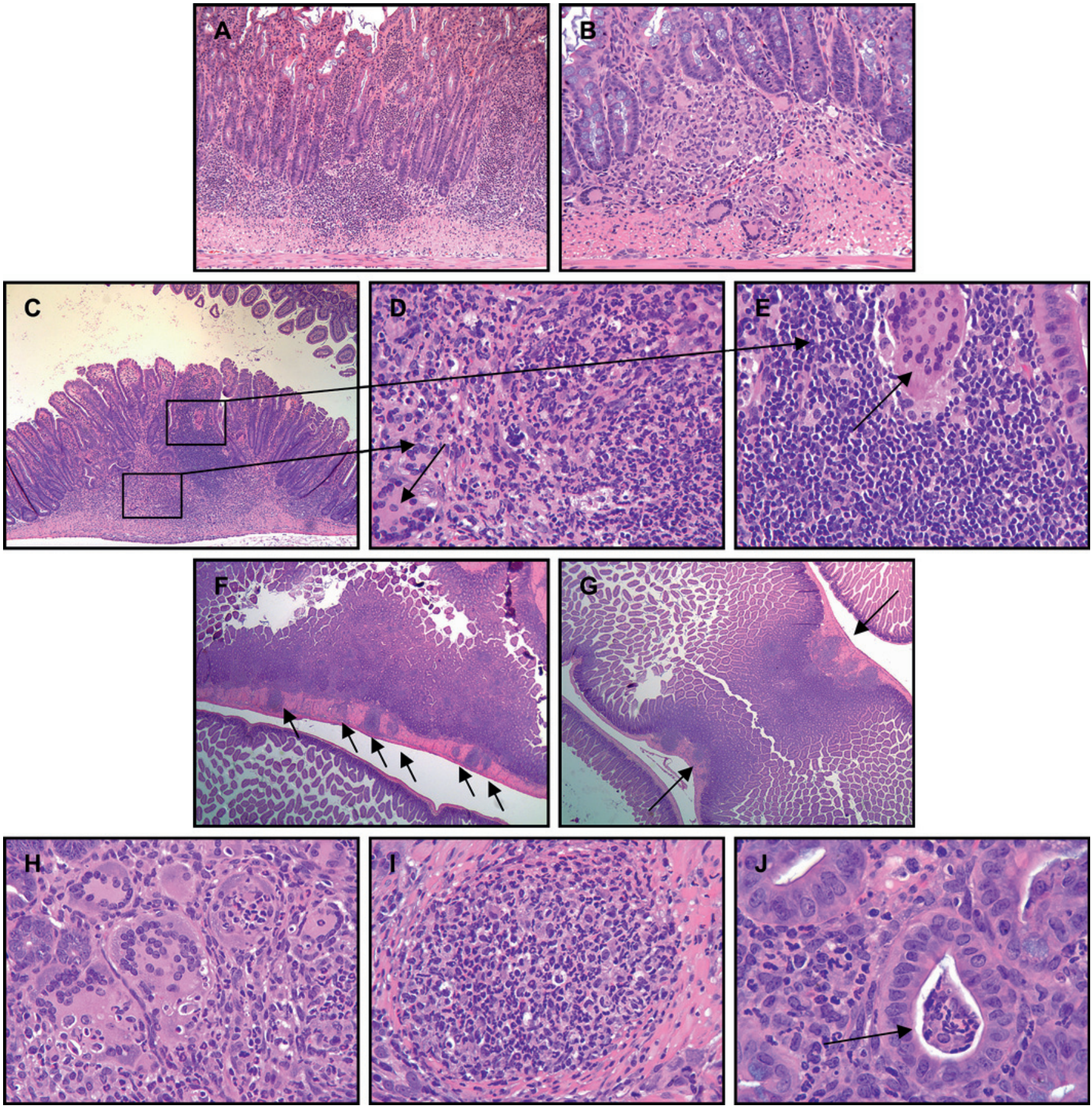

Figure 4 Grade 4 Crohn's disease-like ileitis of SHIP-deficient mice was comprised of a marked, mixed inflammatory cell infiltration of the ileum extending through the mucosa, submucosa, and into the tunica muscularis $(A, B, C, F, G)$. Such inflammatory cell infiltrations varied in composition, were in some areas of affected ileum predominantly polymorphonuclear (D), while in other areas were predominantly mononuclear with lymphocytes, histiocytes and numerous multi-nucleated giant cells present $(B, E)$. Grade 4 ileitis was typically sharply delimited aggregates of pyo-granulomatous inflammatory cell infiltrations, at times in rosary-bead arrays ( $F$, arrows), that caused thickening of the bowel wall $(G$, arrows) and lumen narrowing. Multinucleated giant cells $(\mathrm{H})$, and pyo-granulomas (I) were frequently present in affected segments, but crypt abscesses ( $\mathrm{J}$, arrow) were less frequently observed.

$\mathrm{SHIP}^{\mathrm{\Delta IP} / \Delta \mathrm{IP}}$ mice was not present in lungs of $\mathrm{SHIP}^{-/-}$hosts reconstituted with WT C57BL/6 BM.

\section{SHIP-deficient haematolymphoid cells transfer ileitis to WT hosts}

To directly test whether SHIP-deficient haematolymphoid cells are responsible for the ileitis observed in SHIP-deficient strains, we adoptively transferred $5 \times 10^{5} \mathrm{SHIP}^{-1-}$ splenocytes to each of six WT C57BL/ 6 hosts. The lungs and intestines were then analysed 1 month later for evidence of pathology. Segmental ileitis similar to that observed in germline SHIP-deficient mice was present in 5 of 6 WT mice that received $\mathrm{SHIP}^{-1-}$ splenocytes with a mean ileitis score of 1.8 (the range of scores was $0-5)$. This analysis demonstrates that SHIP-deficiency of the haematolymphoid compartment is sufficient to alter enteric immune cell homeostatic responses in the small intestine resulting in a CD-like phenotype. Interestingly, adoptive transfer 

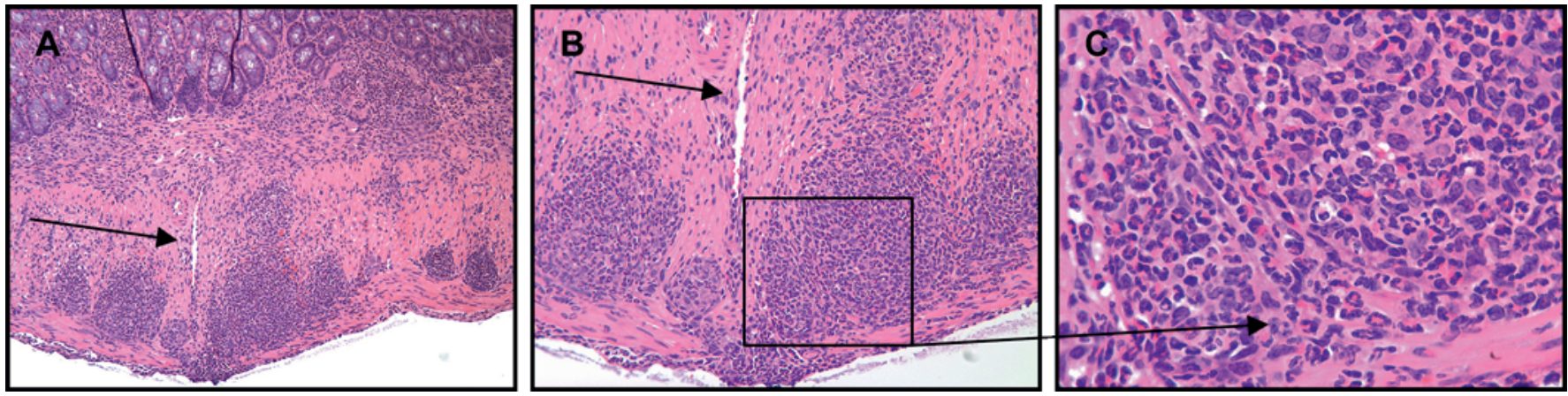

Figure 5 Grade 5 Crohn's disease-like ileitis of SHIP-deficient mice consisted of marked, mixed, transmural inflammatory cell infiltrations that extended to the serosa, some of which due to bowel wall thickening and stricture formation had developed fissures that penetrated into and ended blindly within the tunica muscularis ( $A$; $B$, arrow).
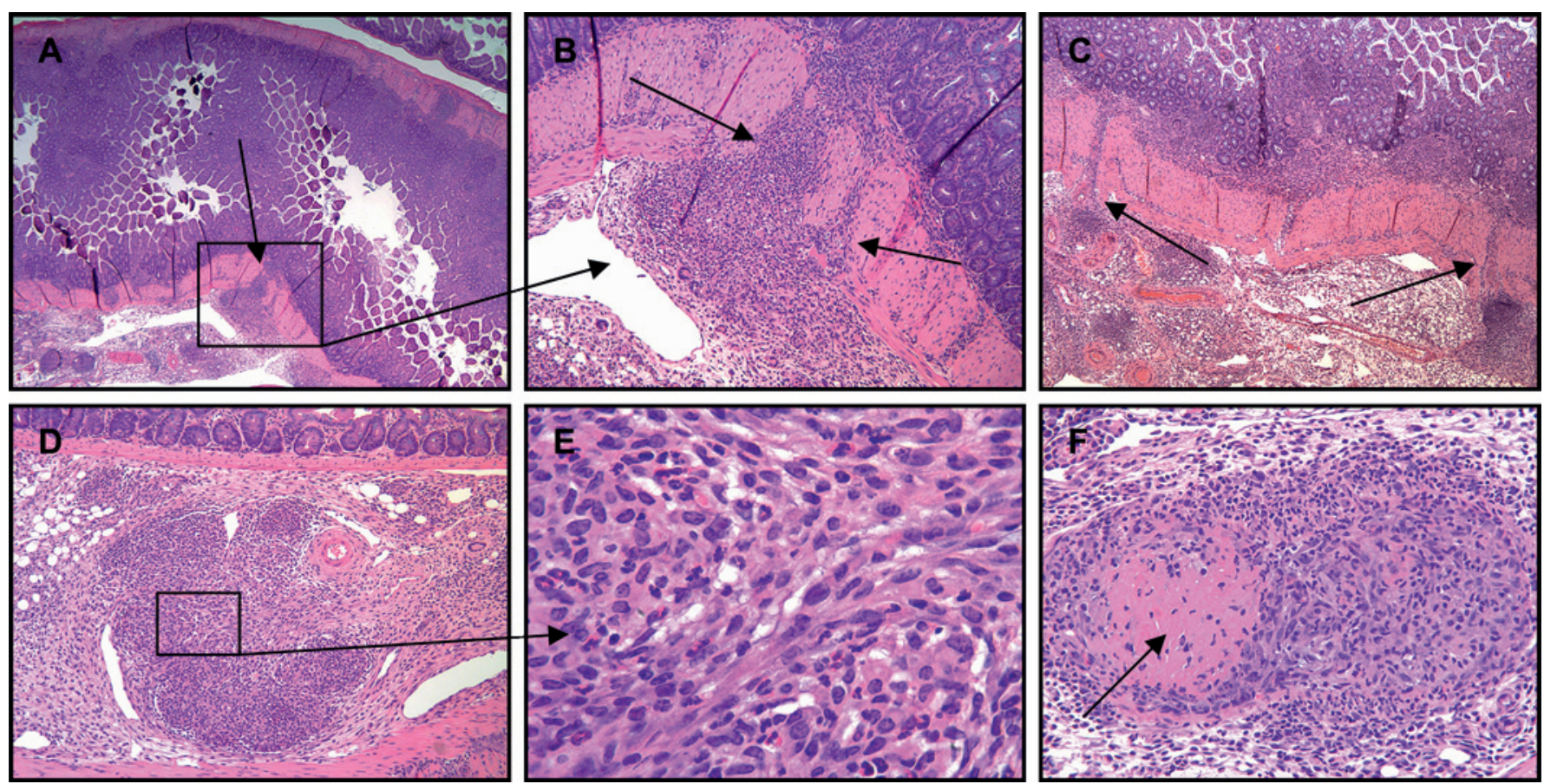

Figure 6 Most SHIP-deficient mice presented with grade 6 Crohn's disease-like ileitis which consisted of marked, mixed, transmural inflammatory cell infiltrations that extended by way of fissures through the ileum serosa into the mesentery ( $\mathrm{A}-\mathrm{C}$, arrows), the inflammation of which was comprised of mixed inflammatory cells and fibroblasts in aggregates and whirls $(E)$, and pyo-granuloma, some with central necrosis $(F$, arrow).
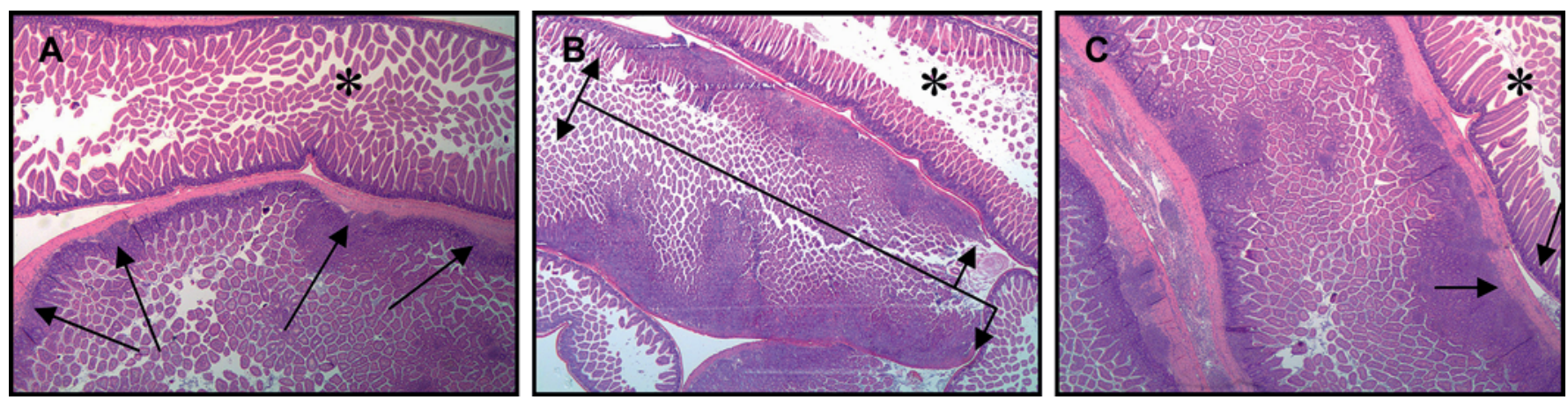

Figure 7 Segmental nature of Crohn's disease-like ileitis of SHIP-deficient mice comprised of either discrete, discontinuous foci of inflammation (A, arrows), or broad bands of inflammation ( $\mathrm{B}$, bracketed arrows), each with expansion of the mucosa and submucosa, and thickening of the tunica muscularis ( $C$, left arrow) compared to neighbouring unaffected segments ( $C$, right arrow; $A, B, C$, asterisks) with normal villous architecture and bowel wall thickness. 
Figure 8 Inflammation extended beyond the ileum in a few SHIP-deficient mice where mixed leucocyte infiltrations of the mesentery infiltrated into the colon wall $(A$, arrow; $B)$, or the juncture of the oesophagus and stomach (C, arrows; D). Draining mesenteric lymph nodes were frequently enlarged and consisted of mixed inflammatory cells with numerous multinucleate cells $(E$, F). Rarely, inflammatory cellular thrombi (T) were present within mesenteric veins ( $G, H$, arrows), and as emboli may have lodged in pulmonary microvasculature resulting in a granulomatous pulmonary consolidation comprised of mixed inflammatory cells with numerous multinucleate cells (I, J, left) that contrasted sharply with the eosinophilic crystalline pneumonia of neighbouring lobes (I, J, right) typical of SHIPdeficient mice.
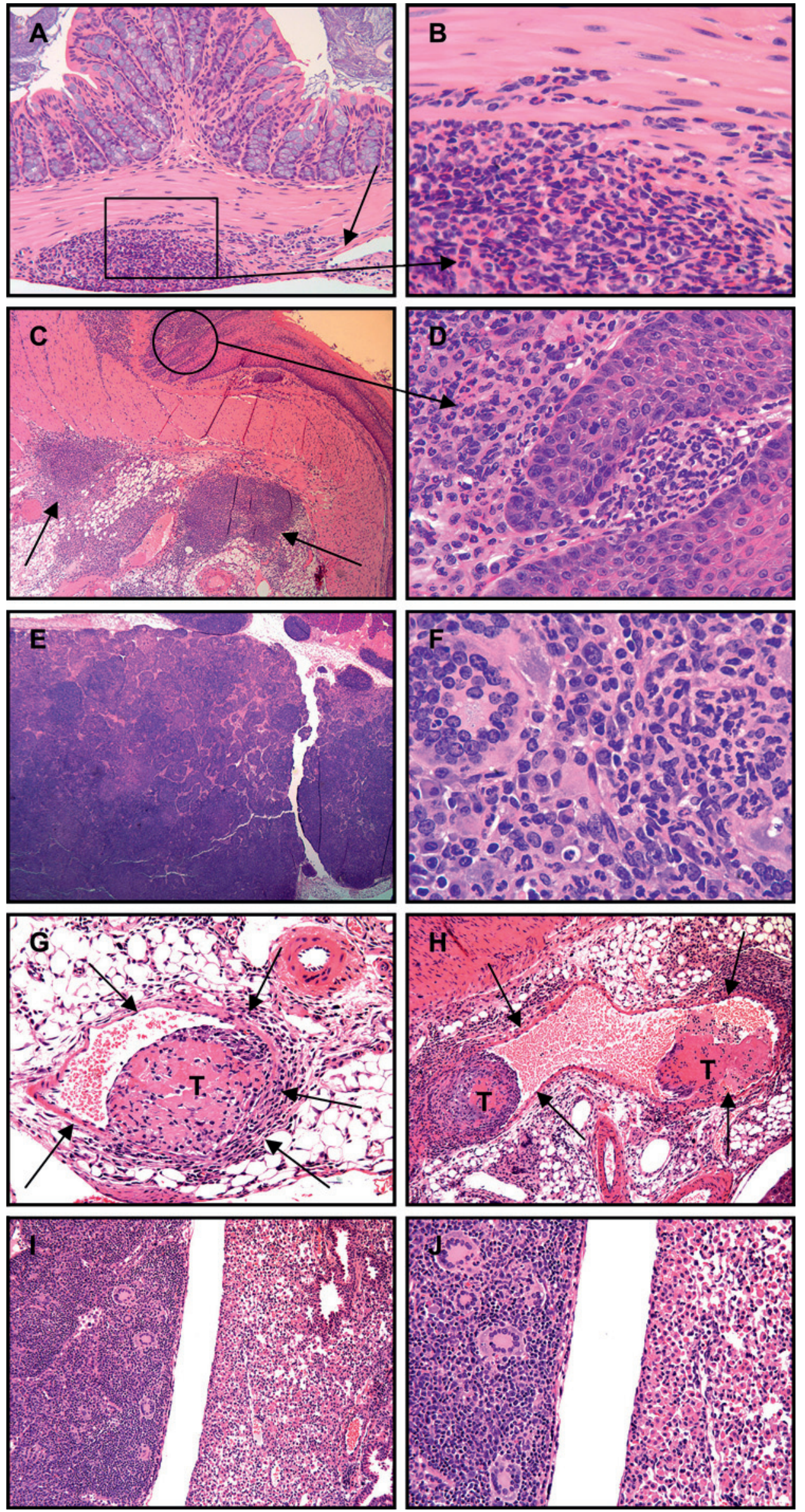
Figure 9 SHIP-deficient mice develop an eosinophilic crystalline pneumonia that consists of large crystals in bronchiolar airways, foci of mixed inflammatory cell infiltrations ( $A$, arrow), bronchiolar subepithelial fibrosis $(B$, arrows), hypertrophy and mucous metaplasia of bronchiolar epithelium (C), numerous alveolar macrophages and multinucleate cells $(D, E)$, and infiltrating leucocytes resulting in patchy pulmonary consolidation ( $\mathrm{F}$, left).
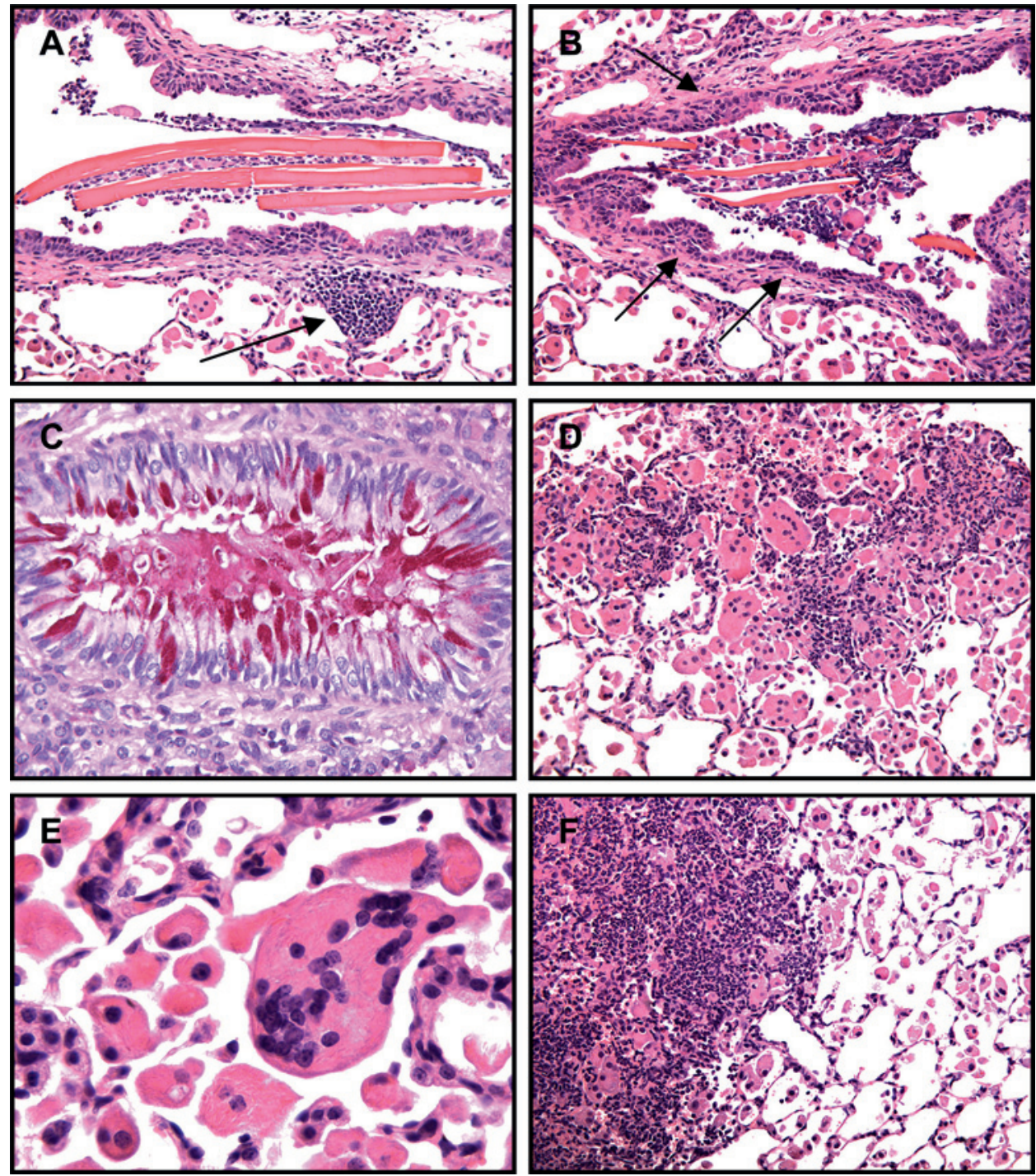

of FACS-purified $\mathrm{CD}^{+} \mathrm{T}$ cells, $\mathrm{NK} 1.1^{+} \mathrm{CD}^{-} \mathrm{NK}$ cells prepared from the spleens of $\mathrm{SHIP}^{-/-}$mice was unable to transfer any detectable ileitis to WT hosts (three hosts analysed per cell type). Thus, SHIP-deficient T cells or NK cells are sufficient for transfer of ileitis. We also observed that $\mathrm{SHIP}^{-/-}$splenocytes transfer a mild to moderate eosinophilic crystalline pneumonia to WT hosts with progression to patchy pulmonary consolidation in some cases as is observed in both germline SHIPdeficient mice ${ }^{41}$ and $\mathrm{MxCreSHIP}$ flox/flox mice following gene ablation. $^{49}$

\section{Neutrophilia combined with T cell paucity in the SHIP-deficient small intestine}

Our pathology findings and adoptive transfer studies described above suggest that a granulocyte-monocyte lineage cell may underlie the ileitis that we observe in SHIP-deficient mice. To further evaluate this possibility, we conducted multi-parametric cytometry assays of major immune cell populations including neutrophils, dendritic cells, CD4/CD8 T cells and Treg cells present in small intestines of SHIP-deficient and WT mice. In support of a role for neutrophils in ileitis, we find there is an absolute increase in total number of neutrophils present in the small intestine of $\mathrm{SHIP}^{-/-}$mice (figure 10). This applied to neutrophils of the $\mathrm{Ly}_{6 \mathrm{G}} \mathrm{C}^{+} \mathrm{CD} 16 / 32^{+}$phenotype as well as the $\mathrm{CD} 2 \mathrm{~L}^{+}$subset (figure $10 \mathrm{~A}, \mathrm{~B}$ ). These findings of ileal neutrophilia are consistent with our histopathology studies described above. Surprisingly, we find a profound reduction in the number of both CD4 (figure 11A) and CD8 (figure 11B) $\mathrm{T}$ cells present in SHIP-deficient small intestines. When paired with the $T$ cell adoptive transfer studies described above, these findings suggest that the CD-like ileitis observed in SHIP-deficient mice is not attributable to an autoimmune attack by SHIPdeficient $\mathrm{T}$ cells. Analysis of $\mathrm{CD} 11 \mathrm{c}^{+} \mathrm{CD} 11 \mathrm{~b}^{+}$mature dendritic cells and $\mathrm{CD} 4{ }^{+} \mathrm{CD} 25^{+}$Treg cells did not show a significant difference in the numbers of these immune cells between $\mathrm{SHIP}^{-/-}$and WT small intestines.

\section{DISCUSSION}

CD pathology begins with the formation of multiple aphthoid ulcers infiltrated by neutrophils, which progress and coalesce into sharply delimited, regional, transmural inflammations with formation of strictures, fissures and fistulas. ${ }^{1-4}$ Here we show that mutation of the SHIP1 locus leads to a comparable ileitis dominated by neutrophils. Although elements of CD pathology are lacking in the SHIP-deficient mouse described herein, including development of multiple aphthoid ulcers, pyloric gland metaplasia, granulation tissue, and fistula formation, many CD histopathological features are present. SHIP-deficient ileitis is not precipitated by an apparent dysfunction on the part of SHIPdeficient parenchymal elements as reconstitution of $\mathrm{SHIP}^{-/}$ 

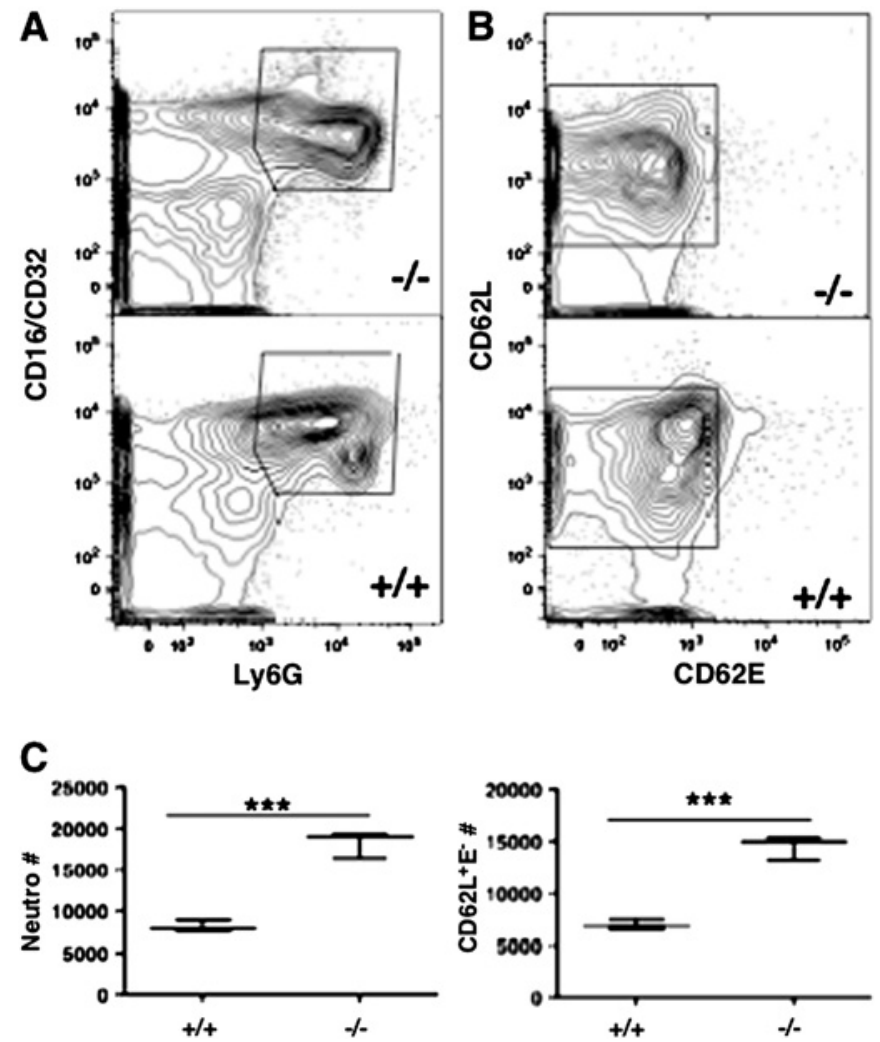

Figure 10 Neutrophilia in SHIP-deficient small intestine. FACS detection of $\mathrm{CD} 16 / 32^{+} \mathrm{Ly}_{6 \mathrm{G}}{ }^{+}$neutrophils $(\mathrm{A})$ and their CD62L/E surface staining $(B)$ in small intestine of SHIP-deficient mice and wild-type (WT) littermates. (C) Absolute total CD16/32 ${ }^{+} \mathrm{Ly}_{6 \mathrm{G}}{ }^{+}$neutrophils and $\mathrm{CD} 62 \mathrm{~L}^{+}$ neutrophils in the small intestine of SHIP-deficient and WT mice as indicated. ${ }^{* *} p<0.001$.

hosts with SHIP-competent haematolymphoid cells prevents development of ileitis. However, these same hosts still retain some facets of eosinophilic crystalline pneumonia indicating that $\mathrm{SHIP}^{-1-}$ parenchymal elements may contribute to the lung pathology found in germline SHIP-deficient mice. Conversely, we find that transfer of SHIP-deficient haematolymphoid cells from the spleen is sufficient to trigger CD-like ileitis in an immunocompetent host. Transfer of cells capable of a cellmediated immune attack, T cells and NK cells, do not elicit this $\mathrm{CD}$-like ileitis. These findings suggest that a SHIP-deficient myeloid cell may promote the CD-like enteritis that occurs in SHIP-deficient mice. Granulocytes are less susceptible to apoptotic signals in SHIP-deficient mice, granulocyte-monocyte infiltrations can be found in various tissues of SHIP-deficient mice, ${ }^{44}$ and mononuclear phagocytes are essential for maintenance of intestinal homeostasis. ${ }^{50}$

Retention of components of eosinophilic crystalline pneumonia in the SHIP ${ }^{-1-}$ hosts reconstituted with WT BM indicates that aspects of this lung pathology are of a parenchymal, cell autonomous origin. Mass spectrometry analyses have identified Ym1 as the principal crystalline protein of this pneumonia, perhaps secreted by activated alveolar macrophages, and proposed to be involved in eosinophil recruitment, immune activation and tissue repair. ${ }^{34}$ However, since SHIP-deficient mice that undergo allogeneic BM transplant have a normal lifespan, ${ }^{32}$ these retained features of pulmonary pathology are apparently not sufficient to progress to the fatal lung consolidation that occurs in germline, SHIP-deficient mice. ${ }^{41}$ Further, with the present observations, CD-like enteritis should be
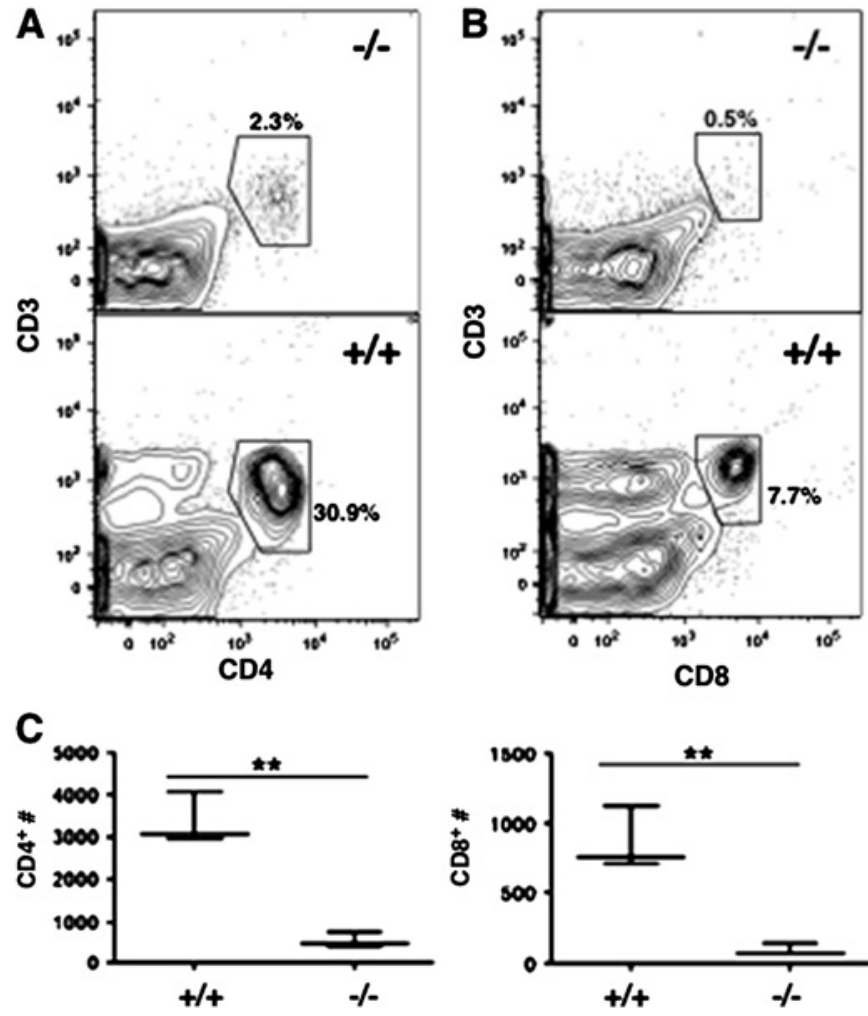

Figure 11 Profound T cell deficit in SHIP-deficient small intestine. FACS detection of $\mathrm{CD}^{+}{ }^{+} \mathrm{CD}^{+}(\mathrm{A})$ and $\mathrm{CD}^{+}{ }^{+} \mathrm{CD}^{+}$(B) T cells in the small intestine of SHIP-deficient mice and their wild-type (WT) littermates. (C) Absolute CD4 and CD8 T cell numbers in the small intestine of SHIP-deficient and WT mice as indicated. ${ }^{* *} \mathrm{p}<0.01$.

included among the pathologies that develop and contribute to morbidity and mortality in germline, SHIP-deficient mice.

The absence of enteric pathology in $\mathrm{SHIP}^{-/-}$hosts reconstituted with WT BM indicates that SHIP-deficiency does not cause an IEC functional barrier defect leading to ileitis. Conversely, that the CD-like phenotype can be transferred to an immunocompetent host by SHIP-deficient haematopoietic cells suggests that SHIP-deficient ileitis is due to an alteration in the regulation of innate immune functions (eg, granulocytemonocyte responses), a failure of T cell mediated mucosal barrier functions or a combination of such potential alterations. Ileitis in SHIP-deficient mice may result from a deficit in mucosal $\mathrm{T}$ cell function that permits inappropriate granulocyte-monocyte responses to commensal organisms and luminal antigens culminating in the inflamed states observed in the ileum of SHIP-deficient mice.

Although the SAMP1/Yit mouse ${ }^{24}$ and the TNF ${ }^{\triangle A R E}$ mouse ${ }^{25}$ spontaneously develop ileitis, the present SHIP-deficient mouse is unique in that it recapitulates the $\mathrm{CD}$ phenotype apparently through perturbation of immune cell populations that can be transferred to a WT host. There are a number of possible candidates for the enteritis-inducing cell. Because we observed neutrophilic infiltrates in the distal ileum lamina propria of most SHIP-deficient mice, we speculate that inappropriate responses by neutrophils to commensal microflora in the lumen of the ileum may underlie or trigger the immune attack. SHIP plays a pivotal role in preventing neutrophilia, as granulocyte numbers in peripheral blood are profoundly increased in SHIP ${ }^{-/}$mice ${ }^{41}$ as well as mice treated with a SHIP1 selective inhibitor, 3AC. ${ }^{49}$ Inappropriate effector function by $\mathrm{SHIP}^{-/-}$neutrophils at organ 
sites has not been examined to date, and thus our findings represent the first indication of neutrophil-mediated tissue damage in SHIP-deficient hosts. Conversely, it seems unlikely that the enteritis results from inappropriate $T$ cell attack in the small intestine, as SHIP-deficiency causes a profound local deficit in both CD4 and CD8 T cell numbers in the small intestine, while normal numbers of Treg cells are still present at this site.

The CD-like pathological findings described above are routinely observed in the ileum of both SHIP $^{-1-}$ strains $^{31} 41$ and the SHIP $^{\mathrm{IID} \Delta \mathrm{IP}}$ strain $^{47}$ that harbour different mutations of the SHIP1 gene indicating this is a highly penetrant phenotype. Moreover, because the phenotype occurs in the SHIP ${ }^{\Delta \mathrm{IP} \Delta \mathrm{IP}}$ strain where only the inositol phosphatase domain encoding exons of SHIP are excised, we conclude that the phenotype is dependent on loss of SHIP enzymatic activity. SHIP through its $5^{\prime}$-inositol phosphatase domain hydrolyses the second messenger $\mathrm{PI}(3,4,5) \mathrm{P}_{3}$ and thus limits PI3K activation of key downstream survival and effector pathways promoted by Akt and NF- $\kappa B .{ }^{30} 40$ However, recent findings indicate that SHIP, via generation of $\mathrm{PI}(3,4) \mathrm{P}_{2}$, can also promote cellular survival by increasing activation of $\mathrm{Akt},{ }^{49}$ consistent with the demonstration that Akt binds to and is more effectively activated by the SHIP product, $\mathrm{PI}(3,4) \mathrm{P}_{2}$, than by its substrate, $\mathrm{PI}(3,4,5) \mathrm{P}_{3}$. ${ }^{51}$ Tiwari et al found that SHIP can also promote immune effector function via synthesis of $\mathrm{PI}(3,4) \mathrm{P}_{2} .{ }^{52} \mathrm{It}$ remains to be determined whether SHIP-deficiency is causing ileitis due to a lack of inhibitory or activating signalling in immune cells. This may be dependent on cellular context. For instance, one could envision that SHIP may be required for efficient mucosal trafficking and survival of T cells via generation of $\mathrm{PI}(3,4) \mathrm{P}_{2}$, but by decreasing $\mathrm{PI}(3,4,5) \mathrm{P}_{3}$ in neutrophils SHIP is also limiting their numbers and function at this enteric site. Future lineage specific SHIP ablation studies using SHIP flox/flox mice and appropriate Cre transgenes combined with biochemical analysis PI3K effector pathways in these models may elucidate the molecular mechanism underlying SHIP's role in preserving normal immune function/regulation in the ileum.

Genetic analysis of mice and genome wide association studies have led to the identification of mutations that can predispose to $\mathrm{CD}$ with varying probability of incidence and timing of onset. Our analysis suggests that in the laboratory mouse, SHIP is a strong genetic determinant of CD-like pathology, suggesting that a similar situation may also be revealed by close examination of SHIP expression and function in CD patients. Tantalising evidence for a role of SHIP1 in human IBD is suggested by the recent demonstration that a chromosome 2 polymorphism located at $2 \mathrm{q} 37$ is associated with a significantly increased and early onset of IBD. ${ }^{53}$ The SHIP1 locus is also found in the $2 \mathrm{q} 37$ region of human chromosome 2 . This potential association merits comparison of SHIP enzymatic activity in IBD patients and normal controls using a recently developed fluorogenic assay that measures SHIP1 activity. ${ }^{49}$ Future investigations of cellular and molecular mechanisms responsible for ileitis in SHIP-deficient mice may also provide insights into how immunological alterations contribute to IBD.

Funding This work was supported in part by grants from the NIH (R01 HL72523, R01 HL085580) and the Paige Arnold Butterfly Run. WGK is the Murphy Family Professor of Children's Oncology Research and a SUNY Empire Scholar.

Competing interests None.

Provenance and peer review Not commissioned; externally peer reviewed.

\section{REFERENCES}

1. Sartor RB. Mechanisms of disease: pathogenesis of Crohn's disease and ulcerative colitis. Nat Clin Pract Gastroenterol Hepatol 2006;3:390-407.
2. Xavier RJ, Podolsky DK. Unravelling the pathogenesis of inflammatory bowel disease. Nature 2007:448:427-34.

3. Packey CD, Sartor RB. Interplay of commensal and pathogenic bacteria, genetic mutations, and immunoregulatory defects in the pathogenesis of inflammatory bowel diseases. J Intern Med 2008;263:597-606.

4. Cho JH. The genetics and immunopathogenesis of inflammatory bowel disease. Nat Rev Immunol 2008;8:458-66.

5. Wirtz S, Neurath MF. Mouse models of inflammatory bowel disease. Adv Drug Deliv Rev 2007:59:1073-83.

6. Barrett JC, Hansoul S, Nicolae DL, et al. Genome-wide association defines more than 30 distinct susceptibility loci for Crohn's disease. Nat Genet 2008:40:955-62.

7. Sollid LM, Johansen FE. Animal models of inflammatory bowel disease at the dawn of the new genetics era. PLoS Med 2008;5:e198.

8. Bouma G, Strober W. The immunological and genetic basis of inflammatory bowel disease. Nat Rev Immunol 2003;3:521-33.

9. Shanahan F. Crohn's disease. Lancet 2002:359:62-9.

10. Monteleone G, Biancone L, Marasco R, et al. Interleukin 12 is expressed and actively released by Crohn's disease intestinal lamina propria mononuclear cells. Gastroenterology 1997:112:1169-78

11. Fuss IJ, Neurath $\mathrm{M}$, Boirivant $\mathrm{M}$, et al. Disparate CD4+ lamina propria (LP) lymphokine secretion profiles in inflammatory bowel disease. Crohn's disease LP cells manifest increased secretion of IFN-gamma, whereas ulcerative colitis LP cells manifest increased secretion of IL-5. J Immunol 1996;157:1261-70.

12. Duerr $\mathbf{R H}$, Taylor $\mathrm{KD}$, Brant SR, et al. A genome-wide association study identifies IL23R as an inflammatory bowel disease gene. Science 2006:314:1461-3.

13. Yen D, Cheung J, Scheerens H, et al. IL-23 is essential for T cell-mediated colitis and promotes inflammation via IL-17 and IL-6. J Clin Invest 2006:116:1310-16.

14. Singh B, Read S, Asseman C, et al. Control of intestinal inflammation by regulatory $T$ cells. Immunol Rev 2001;182:190-200.

15. Kazemi-Shirazi L, Gasche CH, Natter S, et al. IgA autoreactivity: a feature common to inflammatory bowel and connective tissue diseases. Clin Exp Immunol 2002:128:102-9.

16. Dieckgraefe BK, Korzenik JR. Treatment of active Crohn's disease with recombinant human granulocyte-macrophage colony-stimulating factor. Lancet 2002; 360:1478-80

17. Lopez-Cubero SO, Sullivan KM, McDonald GB. Course of Crohn's disease after allogeneic marrow transplantation. Gastroenterology 1998:433-40.

18. Hisamatsu T, Suzuki M, Reinecker HC, et al. CARD15/NOD2 functions as an antibacterial factor in human intestinal epithelial cells. Gastroenterology 2003;124:993-1000.

19. Cadwell K, Liu JY, Brown SL, et al. A key role for autophagy and the autophagy gene Atg1611 in mouse and human intestinal Paneth cells. Nature 2008; 456:259-63.

20. Cario $\mathbf{E}$, Podolsky DK. Differential alteration in intestinal epithelial cell expression of toll-like receptor 3 (TLR3) and TLR4 in inflammatory bowel disease. Infect Immun 2000;68:7010-17.

21. Pizarro TT, Michie MH, Bentz M, et al. IL-18, a novel immunoregulatory cytokine, is up-regulated in Crohn's disease: expression and localization in intestinal mucosal cells. J Immunol 1999;162:6829-35.

22. Olson TS, Reuter BK, Scott KG, et al. The primary defect in experimental ileitis originates from a nonhematopoietic source. J Exp Med 2006;203:541-52.

23. Strober W, Fuss IJ, Blumberg RS. The immunology of mucosal models of inflammation. Annu Rev Immunol 2002;20:495-549.

24. Matsumoto S, Okabe Y, Setoyama $\mathrm{H}$, et al. Inflammatory bowel disease-like enteritis and caecitis in a senescence accelerated mouse P1/Yit strain. Gut 1998:43:71-8

25. Kontoyiannis $\mathbf{D}$, Pasparakis M, Pizarro $\Pi$, et al. Impaired on/off regulation of TNF biosynthesis in mice lacking TNF AU-rich elements: implications for joint and gutassociated immunopathologies. Immunity 1999;10:387-98.

26. Kosiewicz MM, Nast CC, Krishnan A, et al. Th1-type responses mediate spontaneous ileitis in a novel murine model of Crohn's disease. J Clin Invest 2001; 107:695-702.

27. Marini M, Bamias G, Rivera-Nieves J, et al. TNF-alpha neutralization ameliorates the severity of murine Crohn's-like ileitis by abrogation of intestinal epithelial cell apoptosis. Proc Natl Acad Sci U S A 2003:100:8366-71.

28. Ho J, Kurtz CC, Naganuma M, et al. A CD8+/CD103high T cell subset regulates TNF-mediated chronic murine ileitis. J Immunol 2008;180:2573-80.

29. Liu L, Damen JE, Ware M, et al. A new player in cytokine-induced signalling Leukemia 1997;11:181-4

30. Kerr WG. A role for SHIP in stem cell biology and transplantation. Curr Stem Cell Res Ther 2008:3:99-106.

31. Wang JW, Howson JM, Ghansah T, et al. Influence of SHIP on the NK repertoire and allogeneic bone marrow transplantation. Science 2002;295:2094-7.

32. Ghansah T, Paraiso KH, Highfill S, et al. Expansion of myeloid suppressor cells in SHIP-deficient mice represses allogeneic T cell responses. J Immunol 2004; 173:7324-30.

33. Paraiso KH, Ghansah T, Costello A, et al. Induced SHIP deficiency expands myeloid regulatory cells and abrogates graft-versus-host disease. J Immunol 2007:178:2893-900

34. Rauh MJ, Ho V, Pereira C, et al. SHIP represses the generation of alternatively activated macrophages. Immunity 2005;23:361-74. 
35. Collazo MM, Wood D, Paraiso KH, et al. SHIP limits immunoregulatory capacity in the T-cell compartment. Blood 2009;113:2934-44.

36. Locke NR, Patterson SJ, Hamilton MJ, et al. SHIP regulates the reciprocal development of T regulatory and Th17 cells. J Immunol 2009:183:975-83.

37. Kashiwada M, Cattoretti G, McKeag L, et al. Downstream of tyrosine kinases-1 and Src homology 2-containing inositol 5'-phosphatase are required for regulation of CD4 +CD25+ T cell development. J Immunol 2006:176:3958-65.

38. Liu D, Zhang T, Marshall AJ, et al. The p110delta isoform of phosphatidylinositol 3kinase controls susceptibility to Leishmania major by regulating expansion and tissue homing of regulatory T cells. J Immunol 2009;183:1921-33.

39. Patton DT, Garden OA, Pearce WP, et al. Cutting edge: the phosphoinositide 3kinase p110 delta is critical for the function of CD4+CD25+Foxp3 + regulatory $T$ cells. J Immunol 2006;177:6598-602.

40. Krystal G. Lipid phosphatases in the immune system [In Process Citation]. Semin Immunol 2000;12:397-403.

41. Helgason CD, Damen JE, Rosten P, et al. Targeted disruption of SHIP leads to hemopoietic perturbations, lung pathology, and a shortened life span. Genes \& Development 1998;12:1610-20.

42. Guo L, Johnson RS, Schuh JC. Biochemical characterization of endogenously formed eosinophilic crystals in the lungs of mice. J Biol Chem 2000:275: 8032-7.

43. Hoenerhoff MJ, Starost MF, Ward JM. Eosinophilic crystalline pneumonia as a major cause of death in 129S4/SvJae mice. Vet Pathol 2006:43:682-8.

44. Liu 0, Sasaki T, Kozieradzki I, et al. SHIP is a negative regulator of growth factor receptor-mediated PKB/Akt activation and myeloid cell survival. Genes \& Development 1999;13:786-91.

\section{Editor's quiz: GI snapshot}

\section{ANSWER}

From the question on page 155

The liver biopsy shows marked iron retention as demonstrated by positive staining with Perl's reagent (figure 1). However, unlike HFE-related haemochromatosis where marked iron accumulation occurs mainly within hepatocytes (figure 2), iron is found predominantly within Kupffer cells and only focally within hepatocytes. This observation, along with the strong

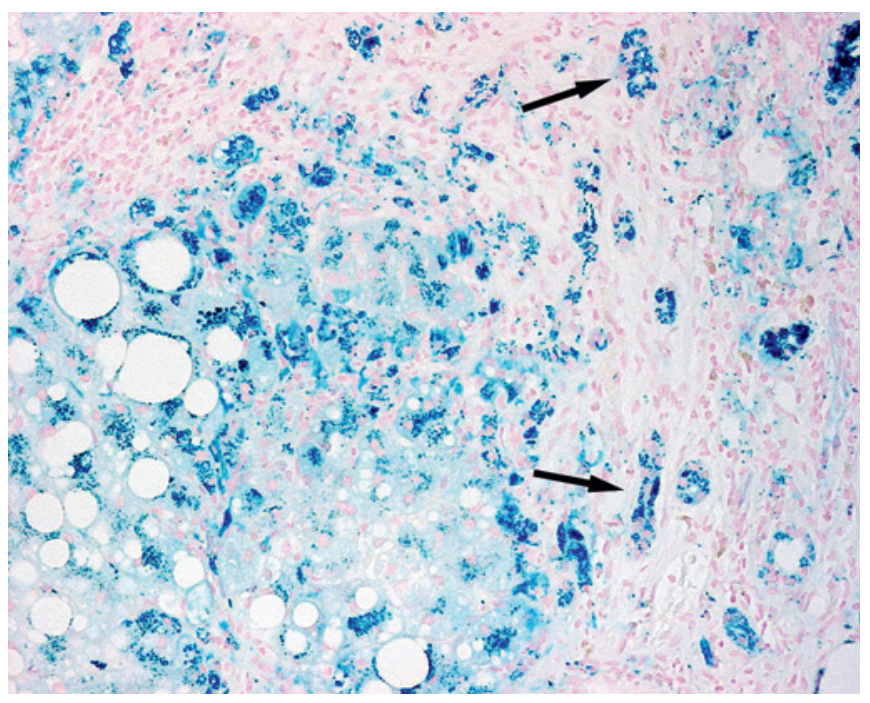

Figure 2 Histological appearances of liver biopsy from patient with HFE-related haemochromatosis, showing marked iron accumulation within hepatocytes as well as within bile duct epithelium (the latter structures are arrowed). Perl's stain. Magnification, $\times 400$.
45. Hazen AL, Smith MJ, Desponts $C$ et al. SHIP is required for a functional hematopoietic stem cell niche. Blood 2009;113:2924-33

46. Zippo A, De Robertis A, Bardelli M, et al. Identification of Flk-1 target genes in vasculogenesis: Pim-1 is required for endothelial and mural cell differentiation in vitro. Blood 2004;103:4536-44.

47. Karlsson MC, Guinamard R, Bolland S, et al. Macrophages control the retention and trafficking of B lymphocytes in the splenic marginal zone. J Exp Med 2003; 198:333-40.

48. Munugalavadla V, Sims EC, Borneo J, et al. Genetic and pharmacologic evidence implicating the p85 alpha, but not p85 beta, regulatory subunit of PI3K and Rac2 GTPase in regulating oncogenic KIT-induced transformation in acute myeloid leukemia and systemic mastocytosis. Blood 2007:110:1612-20.

49. Brooks R, Fuhler GM, lyer S, et al. SHIP1 inhibition increases immunoregulatory capacity and triggers apoptosis of hematopoietic cancer cells. J Immunol 2010; 184:3582-9.

50. Varol C, Zigmond E, Jung S. Securing the immune tightrope: mononuclear phagocytes in the intestinal lamina propria. Nat Rev Immunol 2010;10:415-26.

51. Franke TF, Kaplan DR, Cantley LC, et al. Direct regulation of the Akt proto-oncogene product by phosphatidylinositol-3,4-bisphosphate [see comments]. Science 1997;275:665-8.

52. Tiwari S, Choi HP, Matsuzawa T, et al. Targeting of the GTPase Irgm1 to the phagosomal membrane via Ptdlns(3,4)P(2) and Ptdlns(3,4,5)P(3) promotes immunity to mycobacteria. Nat Immunol 2009:10:907-17.

53. Imielinski M, Baldassano RN, Griffiths A, et al. Common variants at five new loc associated with early-onset inflammatory bowel disease. Nat Genet 2009:41:1335-40.

\section{REFERENCES}

1. Weiss G. Genetic mechanisms and modifying factors in hereditary hemochromatosis. Nat Rev Gastroenterol Hepatol 2010;7:50-8.

2. Zoller H, McFarlane I, Theurl I, et al. Primary iron overload with inappropriate hepcidin expression in V162del ferroportin disease. Hepatology 2005;42:466-72.

3. Pietrangelo A, Corradini E, Ferrara F, et al. Magnetic resonance imaging to identify classic and nonclassic forms of ferroportin disease. Blood Cells Mol Dis 2006:37:192-6

family history, absence of previous blood transfusions, normal ransferrin saturation and normal HFE genotyping suggests nosis of ferroportin disease. loss-of-function and gain-of-function mutations, respectively. Several SLC40A1 gene mutations have been described and ou the basolateral surface of enterocytes and regulates release of iron from hepatocytes and macrophages. With loss of function, becomes 'trapped' in macrophages, resulting in predomihepatocytes (figure 1). In contrast to HFE-related C282Y

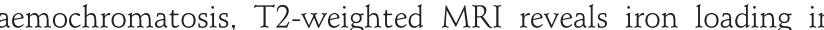
ferroportin disease is poorly characterised, venesection tends to be reserved for those with evidence of liver damage (ie, fibrosis) on biopsy.

Gut 2011;60:188. doi:10.1136/gut.2010.221499 